ESTUDOS R:EP

\title{
Ruptura e efeitos do contrato didático numa aula de resolução de problemas algébricos
}

Lucia de Fátima Araujo

Anna Paula de Avelar Brito Lima

Marcelo Câmara dos Santos

\section{Resumo}

Investiga as relações entre contrato didático e metacognição na resolução de problemas algébricos, numa classe de $8^{\circ}$ ano do ensino fundamental. Evidencia e reflete sobre as rupturas e os efeitos produzidos na negociação do contrato, conforme Guy Brousseau, no âmbito da didática da matemática, analisando sua natureza, as implicações no processo de ensino-aprendizagem, como eles interferem na resolução de problemas algébricos pelos alunos e como influenciam a negociação do contrato e da gestão da relação didática pelo professor.

Palavras-chave: contrato didático; efeitos de contrato; resolução de problemas algébricos. 


\section{Abstract \\ Rupture and the didactic effects of the contract in an algebra pro- blem solving class}

The study investigates the relations between didactic contract and metacognition in the algebra problem solving in an $8^{\text {th }}$ grade class of an elementary school. It shows and reflects about the ruptures and the produced effects in the contract negotiation according to Guy Brouseeau, concerning didactics and Math, analyzing its nature, the learning process implications and their interference in the students algebra problem solving as well as in the management of the didactic relation by the teacher.

Keywords: didactic contract; contract effects; algebra problem solving.

\section{Introdução}

Ao refletirmos sobre o universo da sala de aula, percebemos que ele é permeado por relações de natureza e complexidade diversas. Os elementos humanos dessa relação são o professor e o aluno, que assumem papéis distintos e complementares: o professor é aquele que vai organizar situações de ensino para os alunos, os quais, espera-se, vão se apropriar do conhecimento que está em cena no jogo didático. Outro elemento que faz parte dessa relação é o saber, que, embora seja um elemento não humano, tem um papel determinante. De uma forma clássica, designamos por saber os conhecimentos constitutivos descritos nos programas escolares, considerando que é com este propósito que se desenvolve um projeto de ensino-aprendizagem, em torno do qual se reúnem o professor e os alunos (Jonnaert, Borght, 2003).

Como afirmaram Jonnaert e Borght (2003), o conteúdo, que na Didática da Matemática é o polo do saber (Chevallard, Bosch, Gascón, 2001), não pode estar ausente de uma relação didática; é ele quem lhe define a identidade. Além disso, segundo esses autores, a relação didática se institui quando a associação entre dois - professor e aluno - passa a ser entre três: o professor, o aluno e o saber.

O ensino, por sua vez, também é o ensino de um saber. Logo, quem ensina ensina um conteúdo, uma determinada disciplina; assim, ao pensarmos na sala de aula, precisamos olhar para quem ensina, para quem aprende e para o que se ensina (Brito Menezes, 2006).

Portanto, apenas a existência do contexto escolar e das relações em sala de aula não seria suficiente para o estabelecimento de uma situação 
didática. ${ }^{1} \mathrm{O}$ que aparece como realmente essencial é o caráter intencional da situação proposta, o fato de ela vir a ser desenvolvida com o propósito explícito de que o aluno aprenda algo.

Considerando os elementos envolvidos no estabelecimento de uma situação didática, Brousseau (1986) propõe, então, a existência de uma relação triangular - o Triângulo Didático - cujos vértices são compostos pelos três elementos centrais: o professor, o aluno e o saber. Esse tripé pode ser analisado de forma triangular, dual ou, ainda, individual.

Analisando a referida triangulação, temos relações que se instituem entre professor-aluno, entre aluno-saber e entre professor-saber, as quais precisam ser compreendidas para que possamos entender o processo de ensino-aprendizagem de um dado conhecimento.

Essa relação criada entre professor e aluno - com vista à apropriação do saber - tem na sua base regras que determinam quais as responsabilidades de ambos os parceiros na relação didática, responsabilidades que irão definir de que forma serão gerenciadas a negociação de significados e, consequentemente, a apropriação do saber. Tais regras constituem o contrato didático (Brousseau, 1986; Chevallard, Bosch, Gascón, 2001).

Para Jonnaert e Borght (2003), o contrato didático ocupa o lugar central no funcionamento da relação didática; ele é o motor principal, "a turbina", como dizia Brousseau na sua linguagem metafórica, que define a dinâmica da relação didática. Da mesma forma, Sarrazy (1995) afirmou que a ideia de contrato didático participa dessa dinâmica; ela tem avançado como elemento central das explicações do disfuncionamento da relação didática. Portanto, o estudo do contrato didático é de grande relevância para que possamos compreender os fenômenos que emergem no processo de ensino-aprendizagem na dinâmica da sala de aula.

\section{Aprofundando a noção de contrato didático}

No âmbito da reflexão acerca das relações contratuais que envolvem o ensino e a aprendizagem de determinado conteúdo de saber, Chevallard, Bosch e Gascón (2001) observaram que o ambiente escolar é por natureza contratual. Para esses autores, podemos falar de um contrato escolar - acordo que se estabelece entre a escola e a sociedade - em que cada instituição de ensino propõe toda uma organização: determinando horários, programas, infraestrutura, etc.

Pode-se falar também do estabelecimento de um contrato pedagógico

${ }^{1}$ Situação didática pode ser definida como o conjunto de relações estabelecidas explícita ou implicitamente entre um aluno ou grupo de alunos, um determinado meio (que abrange eventualmente instrumentos ou objetos) e um sistema educativo (representado pelo professor), com a finalidade de conseguir que esses alunos se apropriem do saber constituído ou em vias de constituição (Brousseau, 1986). que visa a ajustar as trocas entre o professor e os alunos, definindo os direitos e deveres recíprocos. A natureza desse tipo de contrato não está ligada a uma disciplina específica, mas às regras que se estabelecem em função do professor e dos alunos. Nesse contrato, ensinar e aprender têm um caráter intransitivo, não se referindo a ensinar e aprender aquele saber específico, como no contrato didático.

Entretanto, quando penetramos na sala de aula, tal organização contratual muda de feição, como assegurou Brito Menezes (2006), e a 
concepção usual de contrato não mais traduz, de forma plena, a relação que se estabelece entre professor e aluno com vista à apropriação do saber escolar. Na sala de aula, essa organização vai se tornando mais implícita e constituindo o que se pode chamar de contrato didático.

Encontramos em Brousseau (1998, p. 61) a seguinte definição de contrato didático:

Uma relação que determina explicitamente, por uma pequena parte, mas, sobretudo, implicitamente, o que cada parceiro, o professor e o aluno, tem a responsabilidade de gerir e pela qual ele será, de uma maneira ou de outra, responsável diante do outro.

Esse autor propõe ainda que o contrato não pode ser completamente explicitado, pois um contrato didático que é totalmente explícito tende ao fracasso. Em particular, as cláusulas da ruptura e o que está em jogo no contrato não podem ser descritos antes. O conhecimento será justamente o que resolverá as crises que surgem das rupturas, e elas não podem ser predefinidas, pois, de acordo com Brousseau (1998, p. 62), "no momento dessas rupturas, tudo se passa como se um contrato implícito ligasse o professor e o aluno".

Lahanier-Reuter (2007, p. 59) definiu de uma forma geral o contrato didático como "o conjunto das regulações e de seus efeitos, reconstruídos a partir das interações entre professores e alunos, resultantes da situação e ligadas aos objetos de saberes disciplinares colocados em jogo nesta situação".

Tais regulações e regras são criadas em função das expectativas que cada parceiro tem quanto ao outro, sempre em relação a um saber. O que o professor espera do aluno? E, nessa mesma direção, o que o aluno espera do professor? Num modelo de ensino tradicional, por exemplo, as expectativas giram em torno da ideia de que se espera do professor que transmita o saber (utilizando, sobretudo, a exposição oral e o quadro e giz) e do aluno, que ouça atentamente, registre e reproduza fielmente em momentos de avaliação da aprendizagem o que o professor ensinou, evitando o erro a todo o custo, pois esse é sinônimo de fracasso.

Portanto, tal contrato implica não só em cada parceiro olhar para si próprio e para o seu papel nessa interação, mas, necessariamente, estabelece que expectativas um tem em relação ao outro e quais as responsabilidades de cada um na gestão do saber.

Nessa direção, Joannert (1994) propõe que há três elementos essenciais a serem considerados no contrato didático: a ideia de divisão de responsabilidades, a consideração do implícito e a relação assimétrica do professor e do aluno quanto ao saber.

Vale ressaltar que, como não existem duas classes idênticas, não podem também existir dois contratos iguais, e, por isso, não há um "modelo" de contrato didático. Além disso, o contrato evolui, muda, se adapta sem cessar aos caprichos da personalidade sempre instável e imprevisível da classe.

Balacheff (1988) definiu a classe como uma sociedade de hábitos (société coutumière), considerando-os como um conjunto de práticas, 
ações e valores estabelecidos pelo uso e que permanecem relativamente presentes nos sistemas escolares. São, portanto, os hábitos de cada classe que vão determinar uma série de regras, sempre implícitas, de funcionamento do grupo (Jonnaert, 1994; Pais, 2001).

Avançando um pouco mais nessa análise, podemos perceber que o contrato didático traz as marcas das relações humanas sobre as relações didáticas, e, portanto, cada professor trará no seu contrato didático as marcas das suas concepções: do que é ensinar, de como se aprende, sobre as estratégias que o aluno deve utilizar para resolver os problemas, etc. Mesmo que o mestre não tenha consciência dessas concepções, elas se revelarão nas suas atitudes em sala de aula, nos sentidos atribuídos às situações e nas suas exigências habituais sobre uma situação particular. A esse respeito, afirma Sarrazy (1995, p. 5): "O contrato didático aparece como o produto de um modo específico de comunicação didática (ligada à epistemologia do professor), instaurando uma relação singular do aluno ao saber matemático e à situação didática."

É importante esclarecer que o contrato didático envolve uma grande quantidade de conceitos referentes às situações didáticas, como também o próprio conceito de contrato didático tem sofrido, desde seu surgimento até os dias atuais, influências das várias correntes filosóficas e epistemologias em voga desde então.

Não temos aqui o objetivo de estabelecer um inventário exaustivo dos diversos usos do conceito de contrato didático, mas de introduzir sua dinâmica interna para compreender melhor os fenômenos aqui estudados. Esse será o nosso próximo ponto de reflexão.

\section{A dinâmica interna do contrato didático}

O contrato didático não existe fora do contexto de uma relação didática, a qual é constituída de uma série de relações sociais, por ele organizadas dentro de um espaço temporal determinado, entre um professor, os alunos e um objeto preciso de ensino e de aprendizagem. O contrato didático gera essas relações sociais particulares, que se colocam em tensão por uma série de rupturas necessárias para permitir a cada uma das partes, professor e alunos, modificar sem cessar sua relação saber. A aprendizagem escolar é sempre fruto dessas rupturas.

A relação didática é caracterizada por relações assimétricas ao saber, e é na existência dessa assimetria que a relação didática encontra sua razão de ser. Longe de condená-las, o contrato didático faz gerar, progredir e evoluir essas assimetrias. Se no início da atividade o professor detém as "chaves" do saber, o aluno, no fim da aprendizagem, deve ter modificado essa relação com o conhecimento; caso contrário, ele não terá aprendido. Dessa forma, a função principal da relação didática é de permitir ao aluno mudar sua relação inicial ao saber.

É fundamental refletir aqui que nem toda relação didática se estabelece da mesma maneira. Em função disso, Pais (2001) apresenta 
três exemplos de contratos didáticos sugeridos por Brousseau, enfatizando as diferentes posturas do professor diante do aluno e da valorização do saber matemático.

No primeiro exemplo, a ênfase é colocada na importância do conteúdo, e a relação professor-aluno reflete essa importância na medida em que o docente se considera com o monopólio do conhecimento e o aluno não sabe nada do que ele vai ensinar. Nesse modelo, as regras do contrato didático são caracterizadas pela predominância de um rígido controle dessa relação, exercido por meio do próprio saber.

No segundo, a ênfase é atribuída mais ao relacionamento entre o aluno e o saber, apenas com um pequeno acompanhamento do professor. Essa postura é a manifestação de uma educação não diretiva, em que não há um efetivo controle do processo de ensino-aprendizagem e a intervenção do professor é mínima, já que cada aluno escolhe livremente sua trajetória, como se a aprendizagem do saber escolar fosse espontânea.

Já no terceiro há também uma forte ênfase no relacionamento do aluno com o saber, mas o professor tenta estabelecer um nível de intervenção bem mais compromissado que no segundo exemplo. Nesse caso, a aprendizagem é considerada tanto em sua dimensão individual quanto em situações envolvendo pequenos grupos ou a classe como um todo. Em tal modelo, o professor não é considerado mais a fonte de conhecimento, como no primeiro exemplo. No entanto, o docente exerce a sua função de acompanhar o processo de aprendizagem, pois é ele quem planeja as situações didáticas, buscando situações desafiadoras adequadas ao nível intelectual do aluno.

Isso, como era de se esperar, confere ao professor um poder indiscutível nessa relação didática; ele não abre mão da sua função docente de mediador do processo de aprendizagem, entretanto, neste percurso, o aluno vai estabelecendo uma relação mais próxima ao saber. Esse último tipo de contrato aponta para uma maior valorização da resolução de problemas, fazendo com que o aluno seja levado a atuar ativamente na elaboração dos conceitos matemáticos.

Ainda no âmbito das reflexões sobre o contrato didático, Sarrazy (1995) levanta uma questão sobre a modificação da relação inicial do aluno ao saber. Para esse autor, quanto mais se coloca para o discente as explicações específicas acerca das regras do contrato - por exemplo, durante a atividade de resolução de problemas - e quanto mais o professor explicita ao aluno o que é esperado dele, menos a aprendizagem tem a possibilidade de acontecer. Segundo Sarrazy, nesse contexto, a situação-problema deixa de ser problemática, já que o aluno sabe o que o professor espera que ele faça.

Dessa forma, a aprendizagem não é mais considerada como o resultado da satisfação das exigências, mesmo implícitas, do contrato didático, mas provém, ao contrário, de uma ruptura dele: "De fato, a aprendizagem vai repousar não sobre o funcionamento do contrato, mas sobre suas rupturas." (Sarrazy, 1995, p. 6).

Vale ressaltar que, muitas vezes, é a ruptura do contrato didático que mais favorece o seu estudo, considerando-se que, quando ele é rompido, 
em geral, "fala-se" algo a respeito dela. Nesse momento, é preciso que o contrato seja revisto e renegociado. Tal renegociação deve implicar uma avaliação e novo direcionamento da prática pedagógica.

Para Jonnaert e Borght (2003), a ruptura didática do contrato tem lugar a partir de uma situação paradoxal, no momento em que um dos parceiros é confrontado com sua própria relação ao saber. Segundo os autores, isso acontece em situações de resolução de problemas, uma vez que o aluno se depara com um obstáculo no seu caminho que só pode ser superado a partir dessa resolução. E, nesse processo, as rupturas são fundamentais para a construção do conhecimento pelo aluno.

Brousseau (1986) corrobora com essa ideia, ao refletir que o mais importante não é tentar explicitar a totalidade das regras que constituem o contrato didático, mas sim delinear alguns de seus possíveis pontos de rupturas.

Para descrever a passagem do "dever de ensinar" ao "dever de aprender", Brousseau (1986) utiliza um conhecido termo jurídico: a devolução. A devolução didática é um ato voluntário no qual o professor coloca o aluno numa situação em que ele deve assumir a sua própria aprendizagem, ou seja, o estudante deve esperar executar o jogo da devolução didática no interior da relação didática, mas ignora os momentos escolhidos pelo professor para provocar essas devoluções. O aluno também pode desejar uma contradevolução; assim, o contrato didático é um jogo de rupturas (devolução versus contradevolução) que faz evocar as relações ao saber do estudante. É por essa dialética que os alunos e o professor criam o dinamismo do contrato didático (Jonnaert, Borght, 2003).

É importante enfatizar que, para que haja essa dinâmica de rupturas didáticas - devolução, contradevolução -, é necessário que exista por parte do professor o projeto de ensinar e que ele encontre seu "corolário" no projeto do aluno, ou seja, de aprender o que o docente ensina.

Ainda a propósito da dialética devolução versus contradevolução, como afirmaram Jonnaert e Borght (2003), o contrato didático propõe bem mais do que uma simples regra que rege a relação didática: uma filosofia de aprendizagem que se localiza dentro do projeto de ensino e de aprendizagem e mostra que o segundo é o corolário do primeiro, desde que os alunos e o professor tenham aceitado participar do jogo.

Vale ressaltar que os estudantes e o professor precisam sentir a eficácia do contrato didático. Segundo Mercier (2005), isso vai pesar sobre as decisões do docente desde o primeiro momento de uma relação didática, porque ele deve mostrar não somente o saber que os alunos devem aprender, mas também que eles aprenderam esse saber; ou seja, o professor deve propor uma tarefa que os alunos consigam realizar, mas que, ao mesmo tempo, pareça nova, para mostrar que eles aprenderam o que ele ensinou.

Colocado em termos práticos, o docente deseja que seus alunos tenham sucesso, e isso pode levá-lo a facilitar a tarefa de diferentes maneiras, gerando, muitas vezes, práticas pedagógicas frequentemente inevitáveis no funcionamento da classe designadas como efeitos do 
contrato. Segundo os estudiosos da didática, esses efeitos são verdadeiras rupturas do contrato, já que impedem a autêntica aprendizagem, como propõe o contrato didático.

Inicialmente podemos citar o efeito Pigmalião, apontado pelos psicólogos educacionais como o fenômeno de expectativas. Brito Menezes (2006) discute que, para Brousseau, esse não seria propriamente um efeito perverso, já que diz respeito a um fenômeno que não se pode evitar quando da instituição de um contrato didático, uma vez que a questão da expectativa de um parceiro em relação ao outro é um dos elementos centrais desse contrato.

Destacaremos de maneira sucinta, a seguir, os principais efeitos (perversos) analisados por Brousseau (1986) na sua proposição teórica.

\section{Os efeitos do contrato didático}

Os principais efeitos analisados por Brousseau (1986) são:

1 - O efeito Topázio, ou o controle da incertitude: é assim denominado porque faz referência a uma cena célebre da peça Topázio, de Marcel Pagnol, cuja passagem diz respeito a um ditado que o professor Topázio faz com um aluno fraco. Nesse ditado, na tentativa de que o discente não cometa erros grosseiros e possa acertar a grafia das palavras, ele, sutilmente, sugere a resposta ao aluno, que compreende os "códigos" e "sinais" do professor e escreve as palavras de forma correta, entretanto, sem a compreensão ortográfica do que faz, mas simplesmente pelas pistas dadas pelo professor.

Esse efeito é bem característico de situações de ensino em que o docente propõe um problema ao aluno, mas, vendo-o em dificuldade, se precipita, fornecendo a resposta.

2 - O efeito Jourdain, ou o mal-entendido fundamental: esse efeito, que pode ser entendido como uma variação do efeito Topázio, é assim denominado por fazer referência à cena de uma comédia-ballet de Molière, que envolve Jourdain e um professor de filosofia. Em virtude do reconhecimento do fracasso iminente do ensino e da não aprendizagem do aluno, o professor atribui a conhecimentos cotidianos do aluno aplicados a situações específicas o status de conhecimentos científicos. Em termos de sala de aula, nesse efeito, um comportamento banal do aluno é interpretado pelo professor como manifestação de um grande saber, e isso termina por desviar a aprendizagem do conhecimento visado.

3 - O deslize metacognitivo: no iminente fracasso de uma atividade de ensino-aprendizagem, o professor pode tomar suas próprias explicações e seus meios heurísticos como objeto de estudo, no lugar do verdadeiro conhecimento matemático. Enquanto no efeito Jourdain o conhecimento 
cotidiano do aluno é tomado como conhecimento científico, no deslize metacognitivo os próprios conhecimentos do professor tomam o lugar do saber.

4 - O uso abusivo de analogia: nesse efeito, o docente tende a substituir o estudo de uma noção complexa pelo de uma analogia. Apesar de ser uma prática natural quando os alunos têm dificuldade na aprendizagem de um determinado conceito - e o professor faz uma analogia com algum conhecimento prévio que o estudante possa ter -, o uso abusivo dessa técnica pode levar o aluno a uma visão limitada do conceito estudado.

Um exemplo típico de analogia no estudo da álgebra escolar é a utilização, pelo professor, da ideia da balança para explicar a equação de primeiro grau. Brito Menezes (2006) discute que, muitas vezes, a balança se converte em uma metáfora inadequada, quando se faz uma utilização "abusiva" dela, no sentido de reduzir uma equação algébrica de primeiro grau a uma balança de dois pratos - ela não serve de analogia, por exemplo, para equações em que apareçam valores negativos, uma vez que não se pode falar em pesagem de quantidades negativas de alguma coisa. Esse efeito, assim como os outros, também culmina por banalizar o saber científico e escolar.

Queremos, por fim, destacar que esses efeitos provocam rupturas no contrato didático. Entretanto, tais rupturas não são aquelas necessárias, muitas vezes, ao aprendizado, pelo fato de que os efeitos são uma distorção na relação professor-aluno-saber - por isso Brousseau os chamou de efeitos perversos do contrato didático.

O olhar que nos propomos lançar sobre os dados do estudo vai na direção, como sugerimos desde o início, de analisar as rupturas e os efeitos do contrato didático na resolução de problemas algébricos. É sobre essa questão que nos debruçaremos a partir de agora.

\section{A pesquisa}

Nessa pesquisa, analisamos os efeitos do contrato didático envolvendo um professor de Matemática e seus respectivos alunos (uma turma de $8^{\circ}$ ano de uma escola da rede particular de ensino da cidade do Recife) na resolução de problemas algébricos a partir das interações discursivas em sala de aula.

Para Câmara dos Santos (1997), a análise do discurso do professor em situação didática pode fornecer os elementos necessários à investigação do contrato didático. Segundo o referido autor, o discurso "captura" os elementos do contrato.

Selecionamos episódios de uma aula em que o professor corrigiu uma ficha de problemas de álgebra (os alunos tinham resolvido a ficha na aula anterior). A lista de problemas (Araújo, 2009) foi entregue ao docente pelos 
pesquisadores, solicitando a sua aplicação. Foi combinado com ele que os alunos não deveriam saber a procedência dos problemas, ou seja, a ficha foi aplicada em sala de aula como um exercício proposto pelo professor, para não comprometer o investimento dos alunos nessa atividade.

A escolha desses problemas foi em função do objetivo de provocar uma ruptura do contrato didático, pois se tratava de problemas diferentes dos modelos que esses alunos estavam acostumados a responder, isto é, não faziam parte do contrato didático dessa sala de aula investigada.

Focaremos nossa análise na correção, feita pelo professor, do seguinte problema:

"Em São Paulo tenho um sobrinho a menos que em Recife. Gastei $\mathrm{R} \$ 200,00$ na compra de presentes para os sobrinhos do Recife e R\$ 120,00 para os de São Paulo. Com isso todos os meus sobrinhos receberam presentes de mesmo valor. Quantos sobrinhos tenho em São Paulo? E no Recife?"

A seguir, apresentamos a resolução do problema feita no quadro pelo professor:

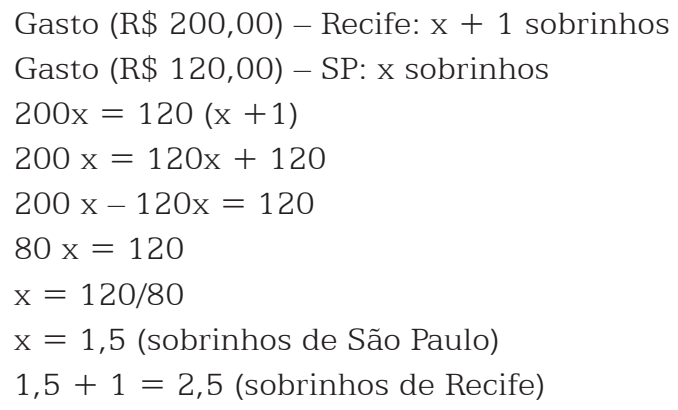

Como constatamos na resolução, esse é um problema possível de resolver pelos procedimentos matemáticos, mas que apresenta um resultado inadequado do ponto de vista da questão solicitada, pois a resposta final (1,5 sobrinho - São Paulo e 2,5 sobrinhos - Recife) não existe na realidade. Problemas desse tipo não são comuns nas salas de aula de Matemática, já que os professores trabalham com problemas cujo resultado faça sentido e responda à questão solicitada, e não com problemas sem solução ou com solução inadequada.

Na correção, observamos que o professor e os alunos discutem sobre o problema e não conseguem chegar a um consenso, como visualizamos nos episódios apresentados a seguir. Os discentes se apresentaram bastante inquietos, falando o tempo todo que o professor errou nos valores dos presentes, já o docente tenta direcionar os alunos para primeiro resolverem o problema como faziam habitualmente durante as aulas de resolução. Isso demonstra que o nosso objetivo foi alcançado: o contrato foi rompido. 
Podemos também, a partir dessa ruptura, perceber mais claramente alguns efeitos do contrato didático instituído nessa classe, como no seguinte episódio:

\section{EPISÓDIO 1}

Prof.: Questão de número 3, pode ler M. Enquanto ela lê, eu quero todo mundo acompanhando, certo?

Aluna M: "Em São Paulo..."

Prof.: Ok, vamos aos dados. M, quanto foi gasto com os presentes em Recife?

Alguns alunos: 200,00.

Prof.: E para os de São Paulo?

Aluno A: 120,00.

Prof.: Pronto, vou anotar aqui.

(E começa a escrever no quadro): Gastei....

Alguns alunos interrompem dizendo: Está errado!

Prof.: Está errado? (começa a ler o problema: "Gastei 200,00 reais na compra...").

Aluno: Ou muda o número de...

Aluno I: Está errada a formulação da pergunta.

Prof.: Não estou entendendo.

Aluno: É assim, um sobrinho a menos...

Prof.: Ah, você já está querendo resolver, eu falei errado alguma coisa?

Aluno I: Eu estou querendo dizer assim: a questão está errada!

Prof.: Calma, a gente nem chegou na questão, eu estou anotando os dados do problema...

(A classe começa a ficar agitada, os alunos discutem em paralelo).

Ao começar com a leitura do problema, o professor buscou, inicialmente, manter o contrato didático estabilizado, como procedia sempre durante a correção: "Questão de número 3, pode ler M. Enquanto ela lê, eu quero todo mundo acompanhando, certo? M, quanto foi gasto com os presentes em Recife?" Ele estabelece a rotina de resolução: "Primeiro escrevemos os dados."

Logo em seguida, os alunos começam a inquietar-se e a falar: "Está errado!", "Está errada a formulação da pergunta", "Eu estou querendo dizer assim: a questão está errada!", "É assim, um sobrinho a menos...", mas o professor contesta: "Calma, a gente nem chegou na questão, eu estou anotando os dados do problema", o que demonstrou que o docente estava em dificuldades para manter estável a situação, revelando com isso indícios do rompimento do contrato.

Em todo esse episódio, vemos claramente o efeito de contrato comumente presente no momento das rupturas: o fenômeno das expectativas, ou seja, tanto o professor quanto os alunos vivem um momento de tensão, por se defrontarem com um problema diferente do que eles estavam acostumados a resolver, o que indica o motivo da ruptura do contrato. 
Observamos também que ambos parecem ter expectativas diferentes de como tratar essa situação nova: o professor quer resolver de acordo com o contrato estabelecido, esperando dos alunos a participação na resolução, mas os alunos, diferentemente do esperado pelo professor, tentam interferir antes de iniciar a resolução, já que conhecem a resposta (resolveram o problema na aula anterior) e sabem que ela é inadequada; como problemas desse tipo não faziam parte do repertório daquela classe (estavam fora das expectativas dos alunos), eles imaginavam que o professor tinha se enganado com os dados do problema.

A aula continua nessa tentativa de renegociação do contrato: o professor buscando, por meio da representação no quadro, estabilizar o contrato, e os alunos tentando verbalizar que existe algo errado com esse problema.

Selecionamos abaixo um episódio no qual podemos identificar mais uma vez o fenômeno das expectativas, que se manifesta, por exemplo, na fala do aluno B:

\section{EPISÓDIO 2}

Aluno B: Veja professor, eu acho que essa fórmula vai ficar meio estranha...

Prof:: Vai ficar estranho, por quê?

Aluno B: Suponha que ele tenha vários sobrinhos.

Igual: $\mathrm{x}=120$ e $\mathrm{x}+1=200 ? \ldots$ Seria $\mathrm{x}=120$ e $\mathrm{x}+1=200$ ?

E mais adiante:

São Paulo 120 reais igual a x, Recife $\mathrm{x}+1=200$ reais. Então, como pode 120 reais ser igual a $\mathrm{x}$ e 200 reais ser $\mathrm{x}+1$ ?

Prof.: Posso fazer uma pergunta? Você concorda com essa armação que a gente colocou aqui?

Aluno B: Bom, concordar eu concordo, mas eu acho estranho.

Aluno I: Eu estou entendendo, professor. Ele está dizendo assim, a armação x e x +1 está certa, o problema são os valores dos reais. Prof.: Os valores?

Aluno I: É esse é o problema, porque não tem lógica...

Esse episódio demonstra a existência de um conflito vivido pelo aluno B, que tenta buscar uma resposta satisfatória para o problema. O professor, por sua vez, parece ter dificuldade em lidar com essa situação e tenta convencer o aluno a primeiro resolver o problema, como fazia no contrato já estabelecido antes da ruptura, usando a representação no quadro. Na última fala do professor isto é bem evidente, quando ele leva o aluno a concordar com o que está escrito no quadro. Já a fala do aluno B mostra a dificuldade de aceitar o que o professor diz: "Bom, concordar eu concordo, mas eu acho estranho." Essa fala pode ser assim traduzida: "Como o senhor é o professor eu concordo, mas continuo sem aceitar isso que está sendo colocado no quadro", reconhecendo o poder do professor na relação didática, mas identificando a incoerência relativa ao saber.

Logo em seguida, o aluno I entra em cena com o mesmo discurso do colega B: "Professor ele está dizendo assim, a armação... está certa, 
o problema são os valores dos reais." E continua: "É, esse é o problema, porque não tem lógica...". Fica evidente, nesse contexto, que os alunos percebem e reagem com estranheza à situação, ou seja, esse tipo de situação fugia às suas expectativas e provocava uma ruptura em relação tanto ao aspecto lógico do problema, como pontuado pelo aluno I, quanto ao próprio professor, do qual se espera sempre saber a "boa resposta" do problema. O docente, por sua vez, procura todo o tempo normalizar/ equilibrar o contrato didático preestabelecido recorrendo à representação no quadro, na expectativa de que os alunos possam participar como faziam nas correções dos problemas habituais.

Por fim, no Episódio 3, o professor tenta renegociar o contrato didático, pois para ele o importante era prosseguir com a resolução:

\section{EPISÓDIO 3}

Prof.: Então, eu vou guardar uma pergunta. A gente vai prosseguir com a resolução e eu vou guardar essa pergunta, está aqui (faz o gesto de colocar simbolicamente no bolso). Está aqui (mostra o bolso para a turma) e, no final, eu vou tirar essa pergunta do bolso e vou perguntar a vocês... está certo? A gente vai prosseguir com o problema, vamos continuar?

Prof.: Todo mundo concordou, e foram vocês mesmos que me disseram que a quantidade de sobrinhos é essa aqui (aponta para o quadro).

(Professor parte para a resolução, conseguindo estabilizar temporariamente o contrato).

Esse artifício usado pelo professor na tentativa de estabilizar a classe - pelo qual ele tirou o foco da atenção dos alunos das discussões sobre o problema, pela dificuldade que se mostrava em dar continuidade ao processo de ensino - gerou um efeito de contrato conhecido na literatura como escorregamento metacognitivo, desviando os alunos das reflexões sobre o problema para aguardar a "suposta" pergunta colocada no bolso.

Apresentamos no próximo episódio os momentos finais da resolução, nos quais encontramos evidenciados outros efeitos de contrato:

\section{EPISÓDIO 4}

Prof.: Vai dar quanto aí?

Alunos: Um e meio!

Prof.: Um e meio? Um sobrinho e meio?

Aluno: Está errado!

Prof.: Eu vou tirar a pergunta do bolso. C, você pode ler mais uma vez o problema, para a gente finalizar?

Aluno C: "Em São Paulo..."

Prof.: A pergunta é: quantos sobrinhos há nas duas cidades? Como é que vocês responderiam esse problema? O problema está corretíssimo, falta agora a resposta! 
(Maior agitação entre os alunos).

Prof.: Se você se deparasse com uma situação dessa e achasse 1,5 , o que você daria como resposta?

Prof.: Olhem para cá, a gente quando resolveu o problema e encontrou 1,5 e 2,5. Para a pergunta que eu vou fazer agora, quero uma resposta convincente. Eu pergunto: De acordo com o problema, qual é a possibilidade, caso tenha, de encontrar o número de sobrinhos? Caso não, justifique.

Aluna M.: Será que um sobrinho mora em 2 lugares?

Prof.: 1 sobrinho mora em 2 lugares?

Prof.: Se eu tivesse 1 saco de confeitos e distribuísse 5 confeitos para um aluno e meio, o que vocês iriam pensar? O que significa meio?

Alunos: Metade (muita agitação na sala).

Prof.: O que é um aluno e meio?

Prof.: Eu pergunto, têm 7 alunos e meio numa sala de aula?

Alunos: Não!

Prof.: Sim, mas eu estou falando, têm 15 alunos e meio nesta sala?

Prof.: Cadê a resposta? Estou esperando a resposta... (o professor fica ouvindo e parece que busca que alguém diga o que ele quer ouvir). Eu quero que vocês pensem na seguinte situação. Veja o que eu vou falar, presta atenção se essa situação é verdadeira: eu vou comprar 1 carro e meio. É verdadeira ou falsa?

Alunos: É falsa.

Prof.: Preste atenção, eu vou escolher na sala 1 aluno e meio? Eu quero sério agora! (alunos discutem entre si, professor ouve um e outro, procurando ouvir alguma coisa...)

Prof.: Olhem para cá, esse número 1,5 representa o quê?

Alunos: Os sobrinhos.

Prof.: Aí, eu pergunto: como é que vocês dariam a resposta sabendo que você encontrou 1 sobrinho e meio, como você daria a resposta?

(Alguém fala lá atrás).

Prof.: Muito bem, L, até que enfim chegou à resposta. Diga alto, por favor.

Aluno L: Não é possível realizar.

Prof.: Por que não é possível realizar?

Aluno L: Porque não têm dados suficientes.

(Professor começa a escrever no quadro):

Não é possível encontrar o $\mathrm{n}^{\circ}$ de sobrinhos!

Nesse último episódio, a tentativa do professor de estabilizar a classe após a resolução levou-o a agir como no contrato preestabelecido, partindo da leitura do problema e propondo questões a fim de obter a resposta esperada. 
Como os alunos pareciam não chegar à solução do problema, o professor procurou, cada vez mais, conduzir as questões para a resposta esperada, dando algumas pistas, como pudemos observar nesse episódio, e ele também monopolizou a fala, fazendo uma sucessão de reflexões, para que os alunos, por meio delas, chegassem à resposta, como demonstra o recorte do episódio:

"Se você se deparasse com uma situação dessa e achasse 1,5, o que você daria como resposta?"

E continua: "De acordo com o problema, qual é a possibilidade, caso tenha, de encontrar o número de sobrinhos? Caso não, justifique."

Prof.: "Se eu tivesse 1 saco de confeitos e distribuísse 5 confeitos para um aluno e meio, o que vocês iriam pensar? O que significa meio?"

Como os alunos não entendem as pistas, ele é mais direto: "O que é um aluno e meio?"

Prof.: "Eu pergunto, têm 7 alunos e meio numa sala de aula?"

Prof.: "... eu estou falando, têm 15 alunos e meio nesta sala?"

E mais adiante: "Eu quero que vocês pensem na seguinte situação. Veja o que eu vou falar, presta atenção se essa situação é verdadeira: eu vou comprar 1 carro e meio. É verdadeira ou falsa?"

Prof.: "Preste atenção, eu vou escolher na sala 1 aluno e meio?"

Prof.: "...como é que vocês dariam a resposta sabendo que você encontrou 1 sobrinho e meio, como vocês dariam a resposta?"

Essa forma de interação, na qual, por meio de pistas, o professor procura guiar a resposta dos alunos, remete-nos a um efeito do contrato, abordado anteriormente, que pode surgir quando o professor não obtém a resposta esperada. Essa tentativa de anunciação da resposta, evitando o fracasso dos estudantes, leva-nos ao efeito Topázio.

Esse último episódio nos deixa a impressão de que o docente estava procurando, por meio dessas perguntas, facilitar de qualquer forma a resposta dos alunos, chegando próximo a anunciá-la a partir das questões propostas, o que bem caracteriza um efeito de contrato didático.

Além desse efeito, percebemos também que o professor procurou conduzir os alunos a chegarem à resposta, devido ao conhecido fenômeno das expectativas que ele tinha em relação àqueles discentes. Contudo, além da sua expectativa, ele, possivelmente, estava preocupado com a da pesquisadora que se encontrava na sala de aula, uma vez que o problema em questão fazia parte de uma ficha que lhe fora entregue pela pesquisadora. Assim, acreditamos que o docente imaginava que a resposta era esperada não só por ele, mas também para a pesquisa que estava sendo realizada.

\section{Considerações finais}

A discussão acerca do contrato didático, como referimos, enfoca que as suas cláusulas, bem como as expectativas de um parceiro da relação 
didática quanto ao outro, tornam-se mais evidentes quando o contrato didático é rompido e que, na tentativa de "salvar" a situação de ensino proposta, o professor muitas vezes incorre em efeitos (perversos) de contrato.

As situações que analisamos neste artigo mostraram, de maneira sucinta, a dinâmica que se institui quando um problema algébrico que foge ao tipo de problema habitualmente proposto é colocado em cena no jogo didático. Pudemos identificar a ruptura em relação às expectativas, sobretudo dos alunos, no sentido de que um professor não propõe um problema matemático que fere uma lógica esperada. A inquietação dos alunos diante do problema revelou o quanto eles se incomodaram ao se depararem com um problema que, embora pudesse ser matematicamente resolvido, não tinha coerência lógica (pensar em "1/5 sobrinho" ou "2/5 sobrinhos").

Ainda que autor da situação, observamos que o professor também se inquietou, por perceber a ruptura evidente e ter clareza de que o problema por ele proposto foi o desencadeador de tal ruptura. Assim, ele buscou, durante todo o tempo, estabilizar o contrato, ora refletindo sobre a natureza matemática do problema, ora destacando a inconsistência lógica. Nesse esforço, o professor incorreu em efeitos de contrato, particularmente o efeito Pigmaleão, já previsto, uma vez que as expectativas foram rompidas, e o efeito Topázio, já que praticamente conduziu os alunos à resposta esperada.

Essas reflexões nos fazem perceber que, embora a literatura aponte que as rupturas são esperadas e necessárias no processo de construção de conhecimento, elas desestabilizam o cenário didático, pois rompem o suposto equilíbrio que se pensa ser necessário à aprendizagem.

Por outro lado, incomoda também nessa relação o fato de o professor ser o desencadeador de tal ruptura. É, em certo sentido, até esperado que o aluno cometa alguns equívocos e incompreensões que possam levar a uma ruptura didática, e isso remete à questão da assimetria entre professor e aluno na gestão do saber. Contudo, espera-se que, no bojo das expectativas que são observadas na relação didática, o professor conduza essa relação da maneira mais estável possível.

Esse desejo de estabilidade plena, entretanto, é questionável, pois se pensarmos numa relação didática (e num contrato didático) cuja problematização seja o ponto de partida, entendemos que se torna inevitável, e até desejável, que haja desestabilizações e rupturas que permitam ao aluno pensar sobre o problema. Nesse contexto, a superação da ruptura e a retomada da estabilidade seriam justamente os indicadores de que o aluno aprendeu algo novo, que a relação com o saber, do aluno e do professor, já não é mais tão assimétrica, apontando, assim, na direção que propôs Margolinas (1993), quando reflete que o objetivo da relação didática é mudar a relação inicial do aluno com o saber.

Queremos, por fim, destacar que toda a análise que fizemos foi a partir de uma aula de matemática e que o referencial teórico que adotamos é o da Didática da Matemática. Entretanto, seria um equívoco pensar que esses fenômenos emergem apenas em salas de aula dessa disciplina. Em qualquer classe, com qualquer saber em jogo - seja da matemática, da língua portuguesa, das ciências naturais ou sociais -, tais fenômenos vão emergir: 
contratos didáticos serão estabelecidos, expectativas serão evidenciadas, rupturas existirão em relação ao saber, efeitos de contrato serão promovidos.

Assim, propusemo-nos com este artigo contribuir para uma reflexão mais ampla, que ultrapasse a sala de aula de matemática e possibilite refletir sobre o ensino e aprendizagem de qualquer campo de saber.

\section{Referências bibliográficas}

ARAÚJO, Lúcia de Fátima. Rompendo o contrato didático: a utilização de estratégias metacognitivas na resolução de problemas algébricos. Tese (Doutorado em Educação) - Universidade Federal de Pernambuco (UFPE), 2009.

BALLACHEFF, N. Le contrat et la coutume, deux registres des interactions didactiques. In : LABORDE (Dir.). Actes du premier colloque Franco-Allemand de didactique des mathématiques et d'informatique. Grenoble: La Penseé Sauvage, 1988. p. 15-26.

BRITO MENEZES, Anna Paula de Avelar. Contrato didático e transposição didática: inter-relações entre os fenômenos didáticos na iniciação à álgebra na $6^{\mathrm{a}}$ série do ensino fundamental. Tese (Doutorado em Educação) - Universidade Federal de Pernambuco (UFPE), 2006.

BROUSSEAU, G. Fondements et méthodes de la didactique. Recherches en Didactique des Mathématiques, n. 7.2, 33-115. La Pensée Sauvage, Grenoble, 1986.

Théorie des situations didactiques. Grenoble, France: La Pensée Sauvage, 1998. Textes rassemblés et préparés par Nicolas Balacheff, Martin Cooper, Rosamung Sutherland et Virginia Warfield.

Le contrat didactique: le milieu. Recherches en Didactique des Mathematiques. v. 9, n. 1, p. 308-336, 1990.

CÂMARA DOS SANTOS, Marcelo. A relação ao conhecimento do professor de matemática em situação didática: uma abordagem pela análise de seu discurso. Anais da 20 Reunião da ASSOCIAÇÃO NACIONAL DE PÓS-GRADUAÇÃO E PESQUISA EM EDUCAÇÃO (Anped). Caxambu, MG, 1997.

CHEVALLARD, Yves; BOSCH, Mariana; GASCÓN, Josep. Estudar matemáticas: o elo perdido entre o ensino e a aprendizagem. Tradução de Daisy Vaz de Moraes, Porto Alegre: Artes Médicas, 2001.

JONNAERT, Philippe. À propos du contrat didactique! Cahiers de Recherche en Éducation, Sherbrooke, v. 1, n. 2, p. 195-234, 1994. 
JONNAERT, Philippe; BORGHT, Cécile Vander. Créer des conditions d'apprentissage: un cadre de réference socioconstructiviste pour une formation didactique des enseignants. Bruxelles: De Boeck, 2003.

LAHANIER-REUTER, Dominique. Contrat didactique. In: REUTER, Yves. (Org.). Dictionnaire des concepts fondamentaux des didactiques. Bruxelles: De Boeck \& Larcier, 2007. p. 59-64. (Éditions De Boeck Université).

MARGOLINAS, Claire. De l'importance du vrai et du faux dans la classe de mathématiques. Grenoble: La Pensée Sauvage, 1993.

MERCIER, Alain. Le contrat didactique et ses effets. Petit vocabulaire raisonné à l'usage des enseignants débutants. Disponível em: < http:/ recherche aix-mrs.iufm.fr/publ/voc/n1/mercier/index.htm>. 2005.

PAIS, Luiz Carlos. Didática da matemática: uma análise da influência francesa. Belo Horizonte: Autêntica, 2001.

SARRAZY, Bernard. Le contrat didactique. Revue Française de Pédagogie, n. 112, p. 85-118, 1995. (Note de synthèse).

Lucia de Fátima Araujo, doutora em Educação pela Universidade Federal de Pernambuco (UFPE), é professora do Departamento de Educação da Universidade Federal Rural de Pernambuco (UFRPE) e participa do Grupo de Pesquisa Fenômenos Didáticos na Classe de Matemática.

luciaaraujo@hotmail.com

Anna Paula de Avelar Brito Lima, doutora em Educação pela Universidade Federal de Pernambuco (UFPE), é professora do Programa de Pós-Graduação no Ensino das Ciências e Matemática da Universidade Federal Rural de Pernambuco (UFRPE) e participa do Grupo de Pesquisa Fenômenos Didáticos na Classe de Matemática.

apbrito@gmail.com

Marcelo Câmara dos Santos, doutor em Educação pela Universidade de Lanterre, Paris, é professor do mestrado em Educação Matemática e Tecnológica (Edematec) da Universidade Federal de Pernambuco (UFPE) e participa do Grupo de Pesquisa Fenômenos Didáticos na Classe de Matemática.

marcelocamaraufrpe@yahoo.com.br

Recebido em 30 de novembro de 2010.

Aprovado em 14 de setembro de 2011. 